\title{
Massive Digital Gene Expression Analysis Reveals Different Predictive Profiles for Immune Checkpoint Inhibitor Therapy Between Adenocarcinoma and Squamous Cell Carcinoma of Advanced Lung Cancer
}

Toshihiko Kaneda ( $\sim$ kaneda.toshihiko.0412@gmail.com )

Kansai Medical University

Takayasu Kurata

Kansai Medical University

Tomoko Yoshida

Ono Pharmaceutical (Japan)

Kayoko Kibata

Kansai Medical University

Hiroshige Yoshioka

Kansai Medical University

Hiroaki Yanagimoto

Kobe University

Kazuhiko Takeda

Ono Pharmaceutical (Japan)

Takao Yoshida

Ono Pharmaceutical (Japan)

Koji Tsuta

Kansai Medical University

Research Article

Keywords: advanced non-small cell lung cancer, nivolumab, anti PD-1 antibody, transcriptome

Posted Date: November 11th, 2021

DOI: https://doi.org/10.21203/rs.3.rs-1035853/v1

License: (c) (i) This work is licensed under a Creative Commons Attribution 4.0 International License.

Read Full License 
Version of Record: A version of this preprint was published at BMC Cancer on February 8th, 2022. See the published version at https://doi.org/10.1186/s12885-022-09264-2. 


\section{Abstract}

Background: Immune checkpoint inhibitors prolong the survival of non-small cell lung cancer (NSCLC) patients.Although it has been acknowledged that there is some correlation between the efficacy of antiprogrammed cell death-1 (PD-1) antibody therapy and immunohistochemical analysis, this technique is not yet considered foolproof for predicting a favorable outcome of PD-1 antibody therapy. We aimed to predict the efficacy of nivolumab based on an exhaustive analysis of RNA expression at the gene level in advanced NSCLC.

Methods: This was a retrospective study on patients with NSCLC who were administered nivolumab at the Kansai Medical University Hospital. To identify genes associated with response to anti-PD-1 antibodies, we grouped patients into responders (complete and partial response) and non-responders (stable and progressive disease) to nivolumab therapy. Significant genes were then identified for these groups using Welch's t-test.

Results: Among 42 analyzed cases (20 adenocarcinomas and 22 squamous cell carcinomas), enhanced expression of MAGE-A4,BBC3 and OTOA genes was observed in responders with adenocarcinoma, and enhanced expression of $D A B 2, H L A-D P B 1$ and $C D H 2$ genes was observed in responders with squamous cell carcinoma.

Conclusions: This study predicted the efficacy of nivolumab based on an exhaustive analysis of mRNA expression at the gene level in advanced NSCLC. We also revealed different gene expression patterns as predictors of the effectiveness ofanti PD-1 antibody therapy in adenocarcinoma and squamous cell carcinoma.

\section{Background}

Approximately $80 \%$ of lung cancers are non-small cell lung cancers (NSCLCs) [1]. Although surgical resection is the most effective therapy for early-stage NSCLC, up to two-thirds of NSCLCs are inoperable. This implies that histological and molecular diagnosis should be established using tiny specimens, such as small biopsy specimens and/or cytological materials,obtained via transbronchial biopsy, fine-needle aspiration or computed tomography (CT) guided biopsy. With the advent of molecular targeted therapies for NSCLCs, specimen requirements continue to increase [2].

Since the discovery of the association betweenepidermal growth factor receptor (EGFR)mutations in NSCLCs and their tyrosine kinase inhibitors, various gene alterations have been identified, and therapeutic agents based on these alterations have shown dramatic effects [3]. A portion of patients without druggable driver oncogenic alterations show dramatic durable responses to immune checkpoint inhibitors (ICls) $[4,5]$. On the contrary, ICl therapy sometimes shows serious side effects such as autoimmune diseases. Therefore, appropriate patient selection is imperative [6]. 
The most commonly used predictor of ICl efficacy is immunostaining for programmed cell death-1 (PDL1) protein. Even in patients with high PD-L1 protein expression, the accuracy of prediction is reported to be only approximately $50 \%$. In addition, some patients without PD-L1 protein expression have shown responses to ICls [7]. Furthermore, there is significant intratumoral, intertumoral, and temporal heterogeneity in PD-L1 protein expression, which can lead to misclassification of PD-L1 status [8]. Some researchers have explored other predictive biomarkers for ICls. Tumor mutation burden is a useful biomarker candidate [9], but its detection requires genetic analysis by next-generation sequencing. The tumor microenvironment is also considered a seminal predictor of the efficacy of ICls.

Comprehensive mRNA profiling is now used to predict the therapeutic effects of ICls and prognosis of malignancies. In fact, comprehensive gene analysis techniques, such as NanoString'sProsigna ${ }^{\mathrm{TM}}$ Breast Cancer Prognostic Gene Signature Assay, are used in daily clinical practice for patients with breast carcinoma and play an important role in therapeutic decisions [10].The NanoString'splatform hybridizes fluorescent barcodes directly to specific nucleic acid sequences, allowing for the non-amplified measurement of up to 800 targets within one sample.

The aim of this study was to retrospectivelyexplore mRNA profiles, considered to be involved in the tumor microenvironment, as a predictor for ICls using NanoString's platform, and to verify whether daily cytological specimens could be effective predictors for ICls.

\section{Methods}

\section{Patients and samples}

We investigated patients with NSCLC who were administered nivolumab at the Department of Thoracic Oncology, Kansai Medical University Hospital (Osaka, Japan). Nivolumab (3 mg/kg) was intravenously administered every two weeks (a cycle) unless progressive disease (PD) or unacceptable toxicity was noted. Patients were followed up at regular intervals for evaluation of recurrence. Chest CT scans were performed every two to three cycles to evaluate the treatment response and disease progression.

Patient characteristics were collected from medical and radiographic records to ascertain age, sex, smoking history, histology, EGFR mutation status, and PD-L1 protein expression status. Tumor response was retrospectively evaluated according to the Response Evaluation Criteria in Solid Tumors version 1.1. Progression-free survival (PFS) duration was calculated from the date of initiation of nivolumab treatment to the date of disease progression or death. Overall survival (OS) time was determined from the date of initiation of nivolumab treatment to the date of death or last follow-up on December 31, 2018.

\section{RNA extraction}

All cytological specimens selected for RNA extraction were those obtained from patients before nivolumab administration. Slide coverslips were detached in xylene, and the slides were rehydrated by successive ethanol washes $(95 \%, 70 \%, 50 \%$, and $30 \%)$, followed by soaking in phosphate-buffered saline 
for $2 \mathrm{~min}$. The slides were then air-dried. Using a new, flat, single-edged razor blade, the entire contents of the slide were scraped into $200 \mu \mathrm{L}$ of phosphate-buffered saline. Tumor enrichment with macrodissection was performed as required. RNA extraction was performed using the QIAamp RNA Blood Mini Kit (Qiagen, Germantown, MD, USA) according to the manufacturer's protocol.

\section{Digital mRNA counts and analysis}

The nCounter assay was performed using the NanoStringnCounter mRNA Gene Expression system and nCounter ${ }^{\circledR}$ PanCancer 10360 Panel (NanoString Technologies, Inc.) according to the manufacturer's instructions. RNA was hybridized with probe sets for $16 \mathrm{~h}$ at $67^{\circ} \mathrm{C}$. The samples were processed using an automated nCounter Sample Prep Station (NanoString Technologies, Inc.). Cartridges containing immobilized and aligned reporter complexes were subsequently imaged on an nCounter Digital Analyzer (NanoString Technologies, Inc.) that had been set at a data resolution of 555 fields of view.

\section{Gene expression analysis}

Reporter counts were subjected to sequential data processing steps using the nSolverTM Analysis Software (version 4.0) according to the manufacturer's instructions. After quality control, background was calculated using the mean +2 standard deviation of the internal negative control counts, and background subtraction was performed. The counts were normalized to internal positive controls to eliminate technical variability of the assay, and then normalized to the geometric mean of endogenous housekeeping genes. The normalized counts were analyzed using Genedata Profiler ver. 12.0.8.

\section{Statistical analysis}

To identify genes associated with response to anti-PD1 antibodies, we grouped patients into responders (complete response and partial response [PR]) and non-responders (stable disease and PD).

PFS and OS curves were generated according to the Kaplan-Meier method using the log-rank test. Statistical analyses were performed using JMP 9 software (SAS Institute Inc., Cary, NC, USA).

Significant genes were then identified for these groups using Welch's t-test (Genedata Profiler ver. 12.0.8). Significantly high expression of mRNA was defined as fluctuated 2 times and genes satisfying $P<0.05$.

Overall, 18 genes related to tumor inflammation signature(TIS) were analyzed by unsupervised hierarchical clustering analysis using R3.6.0. Samples and genes were clustered using the Ward method based on Manhattan distance and Pearson distance, respectively.

\section{Results}

\section{Patients and samples}

A total of ninety-three patients received nivolumab between December 2015 and March 2018. Only adenocarcinoma or squamous cell carcinoma 46 cases with extra cytological slides were selected, 
considering the exhaustion of formalin-fixed paraffin-embedded blocks for previous companion diagnostics and specimen storage for future clinical trials. During the molecular analysis, four cases with low quantities of mRNA or abnormal signals were excluded, and the final cohort consisted of 42 cases (20 adenocarcinomas and 22 squamous cell carcinomas).

The clinical characteristics of the 42 patients are presented in Table 1. The median age was 69 years (range, 43-85 years). Most patients were male (34/42, 81.0\%) and had smoked (37/42, 88.1\%) at some point. Squamous cell carcinoma (22/42, 52.48\%) was predominant. EGFR mutations were detected in two cases $(2 / 42,4.8 \%)$. As there is essentially no need to confirm EGFR mutation in squamous cell carcinoma, the EGFR mutation status of many of the cases $(18 / 42,42.8 \%)$ remains unknown. Further, during the study period (between 2015 and 2018), measurement of ROS1 and BRAF mutations was not covered and required by the insurance system. Moreover, there were few residual specimens. As a result, additional confirmation of these mutations was not possible.Most patients received nivolumab as second-line chemotherapy (22/42,52.4\%), and the mean number of chemotherapy cycles was 9 (range, 1-64 cycles).However, measurement of PD-L1 was not mandatory in second-line chemotherapy with nivolumab and beyond during this study period, and there were few residual specimens, making additional confirmation impossible. As a result, the PD-L1 status was also predominantly unknown $(32 / 42,76.2 \%)$.

Most of the cytological materials analyzed consisted of brush from bronchoscopy $(29 ; 69.1 \%)$ followed by imprinting from transbronchial biopsy $(8 ; 19 \%)$, fine needle aspiration from lymph node deposit (4; 9.5\%), and imprinting from CT-guided biopsy $(1 ; 2.4 \%)$.

\section{Treatment efficacy}

The antitumor activity results are summarized in Table 2 . The overall response rate (ORR) was $42.8 \%$, and the overall disease control rate was $69.0 \%$. In adenocarcinoma, 7 cases with PR were assigned to responders, and the remaining 13 cases were assigned to non-responders. In squamous cell carcinoma, 11 cases with PR were assigned to responders, and the other 11 cases were assigned to non-responders.

Table 3 shows the differences in ORR due to each clinicopathological factor. There was no significant difference in response rate according to the histological type. There were two cases withEGFR mutations, both of which were PD. There were two PD-L1 negative cases, both of which were evaluated for PR.

In all patients, the median PFS was 4.32 months (95\% confidence interval [CI]: $2.80-10.5)$ (Fig. 1A). The median OS was not reached (95\% Cl: 21.5-not reached) (Fig. 1B). There was no significant difference in median PFS between histological subtypes (adenocarcinoma; 5.70 months, 95\% Cl: 2.33-15.4 and squamous cell carcinoma; 3.85 months, $95 \% \mathrm{Cl}$ : 1.87-11.6, $p=0.386$; Fig. $1 \mathrm{C})$. There was no significant difference in median OS between histological subtypes (adenocarcinoma; 23.4 months, 95\% Cl: 7.97-not reached and squamous cell carcinoma; not reached, 95\% Cl: 23.2-not reached, $p=0.458$; Fig. 1D).

\section{Expression profiles of adenocarcinoma and squamous cell carcinoma}


Volcano plot of $p$-value versus log2 fold change of the differential expression between responders and non-responders in adenocarcinoma revealed that the numbers of genes with high expression in responders and non-responders werefour and five, respectively (Fig. 2A). In squamous cell carcinoma cases, the corresponding numbers were 12 and 5 (Fig. 2B).

\section{T cell-inflamed 18 gene expression profile}

Unsupervised hierarchical clustering analysis data between responders and non-responders are shown for all cases (Fig. 3A), adenocarcinoma (Fig. 3B), and squamous cell carcinoma (Fig. 3C). In all cases, no significant cluster formation was observed. No significant cluster formation was observed even when adenocarcinoma and squamous cell carcinoma data were separately analyzed.

\section{Discussion}

In this study, we demonstrated that massive digital gene expression analysis can be performed using cytological specimens. We also revealed that different gene expression patterns are a predictor of the effectiveness of $\mathrm{ICl}$ therapy in primary lung adenocarcinoma and squamous cell carcinoma.

The results of the study show that massive digital gene expression analysis can be successfully applied to previously Papanicolaou-stained cytological materials. Although diagnostic imaging is developing, approximately $70 \%$ of lung cancer patients are detected with unresectable disease. Therefore, diagnosis must be based on small biopsy and/or cytology specimens [11]. The 'bioresource' used for the detection of molecular targets can be largely wasted by using this molecular approach (e.g. multiple tissue sections, dissection for tumor cell enrichment) [2]. Our result sheds light on the usefulness of cytological specimens for molecular diagnostics as well as the effective use of limited specimens [12].

We could not draw a consistent conclusion because the timing of sample collection and the timing of ICI treatment were not constant. All patients received at least one chemotherapy regimen, suggesting that those with a strong effect of cell damage from chemotherapy are more suitable for ICI therapy. Although the effectiveness of the combination of chemotherapy and ICls has been reported [13], this mechanism may enhance it.

Among the four genes that were significantly highly expressed in the responders with adenocarcinoma, MAGE-A4 and BBC3 were noticeable. MAGE-A4 has been reported to have the potential to serve as a biomarker and valuable target for immunotherapy [14]. Further, it has been reported as a target for T-cellbased immunotherapy, especially for NSCLC or triple-negative breast cancer [15], and thus it may be a potential biomarker for the therapeutic effect of ICls. However, further data are needed.

Among the 12 genes that were significantly highly expressed in responders with squamous cell carcinoma, DAB2 and human leukocyte antigen $H L A-D P B 1$ genes were related to antigen presentation and immune response, respectively. In particular, the $H L A-D P B 1$ gene encodes a protein that plays a critical role in the immune system. Expression of HLA molecules in cancer cells seems to be a key factor 
in the presentation of tumor-associated antigens to T lymphocytes [16]. Alterations of these molecules by the tumor cells are one of the important immune-escape mechanisms [17]. These facts suggest that ICls may be more effective in cases of squamous cell carcinoma with excessive antigen presentation.

In non-responders with squamous cell carcinoma, $\angle A M B 3$, ITGB8, and WNT5A genes were highly expressed. These genes are reported to be involved in tumor invasion via Rac and Rho cascades $[18,19]$. Activation of the extracellular matrix and cell adhesion-related genes enhances cell motility and reduces the effect of immunotherapy. In addition, high adrenomedullin (ADM) expression was observed in the non-responder group. ADM is expressed in a variety of tissues, such as the adrenal gland, heart, and lung [20]. ADM regulates vascular tone and proliferation of fibroblasts and vascular smooth muscle cells [21]. Although there was no clinicopathological correlation, high ADM protein expression was observed in lung squamous cell carcinoma [22]. Increasing systemic levels of vasoactive peptides, including pro-ADM, are associated with improved tumor response in metastatic colorectal carcinoma patients treated with a bevacizumab-containing regimen [23]. Vascular endothelial growth factor not only promotes angiogenesis but also causes immunosuppression in the cancer microenvironment [24]. The efficacy of combination therapy with ICls and antiangiogenic agents has been reported [25]. This fact suggests that antiangiogenic agents enhance the effects of $\mathrm{ICl}$ as well as inhibit angiogenesis in a portion of squamous cell carcinomas.

Recently, the utility of a TIS consisting of 18 genes using the same NanoString platform for predicting the therapeutic effect of anti-PD-1 treatment was reported [26] and its utility has been verified in various tumors [27]. However, our cluster analysis did not confirm the utility of these 18 genes. Furthermore, the differences between responders and non-responders were evaluated by the average value of the log scores of each gene'sexpression, but no statistical difference was observed (data not shown). One possible reason is that each gene is not weighted because its detailed algorithm has not been clarified.To the best of our knowledge, this study is the first to examine each histological type of adenocarcinoma and squamous cell carcinoma using a heatmap of the differential expression between responders and non-responders.

Retrospective analysis and a small sample size were limitations of the current study. Another weakness is that the time of collection and the period until drug administration were not constant. In addition, there are few cases in which known predictors, such as PD-L1 immunohistochemical status and tumor mutation burden,were analyzed; thus, an effective comparison was not possible.

\section{Conclusions}

This study aimed to predict the efficacy of nivolumab based on an exhaustive analysis of RNA expression in advanced NSCLC, finding that different gene expression patterns are predictors of the effectiveness of anti PD-1 antibody therapy in adenocarcinoma and squamous cell carcinoma.

\section{Abbreviations}


NSCLC: non-small cell lung cancer; EGFR: epidermal growth factor receptor; ICl: immune checkpoint inhibitor; PD-1: programmed cell death-1; PD: progressive disease; CT: computed tomography; PFS: progression-free survival; OS: overall survival; PR: partial response; ORR: overall response rate; $\mathrm{Cl}$ : confidence interval; ADM: adrenomedullin; TIS: tumor inflammation signature

\section{Declarations}

Ethics approval and consent to participate: All methods were conducted in accordance with the Declaration of Helsinki and Japanese regulations. This study protocol was approved by the Institutional Review Board (IRB) of Kansai Medical University Hospital (approval number: 2018051).Informed consent to participate in the study was obtained from subjects by opt-out style.

Consent for publication: Not applicable.

Availability of data and materials: All data generated or analyzed during this study are included in this published article. All the data were available from the corresponding authors for reasonable request.

Competing interests: TK received personal fees from AstraZeneca, Boehringer Ingelheim, Bristol Myeres, Chugai, Eli Lilly, MSD, and Ono Pharmaceutical Co., Ltd. Kurata T received grants from AstraZeneca, Eli Lilly, MSD, Ono Pharmaceutical Co., Ltd., and Takeda Pharmaceutical Company, outside the submitted work. KT received personal fees from AstraZeneca, Janssen Pharmaceutical K.K., MSD, Novartis, and Roche. TY, KT, and TY are paid employees of Ono Pharmaceutical Co., Ltd.Other authors have no conflicts of interest to declare.

Funding: This study was funded by Ono Pharmaceutical, Co., Ltd.

Authors' contributions: All authors designed the concept of the study. TK, TK, TY, TY, and KT collected the data and analyzed the data.TK, TY, and KT wrote the initial manuscript.TK, TK, TY, TY, and KT participated in the manuscript revision and data analyses.All authors participated in the manuscript writing and approved the final manuscript.

Acknowledgements: The authors thank Ryosuke Yamaka for technical assistance.

\section{References}

1. Travis WD, Brambilla E, Burke AP. WHO classification of tumours of the lung, pleura, thymus and heart. Lyon, France: IARC Press; 2015.

2. McCall SJ, Dry SM. Precision pathology as part of precision medicine: Are we optimizing patients' interests in prioritizing use of limited tissue samples? JCO Precis Oncol. 2019;3:1-6.

3. Majeed U, Manochakian R, Zhao Y, Lou Y. Targeted therapy in advanced non-small cell lung cancer: Current advances and future trends. J Hematol Oncol.2021;14:108. 
4. Brahmer J, Reckamp KL, Baas P, Crinò L, Eberhardt WEE, Poddubskaya E, et al. Nivolumab versus docetaxel in advanced squamous-cell non-small-cell lung cancer. N Engl J Med.2015;373:123-35.

5. Reck M, Rodríguez-Abreu D, Robinson AG, Hui R, Csőszi T, Fülöp A, et al. Pembrolizumab versus chemotherapy for PD-L1-positive non-small-cell lung cancer. N Engl J Med.2016;375:1823-33.

6. Darnell EP, Mooradian MJ, Baruch EN, Yilmaz M, Reynolds KL. Immune-related adverse events (irAEs): Diagnosis, management, and clinical pearls. Curr Oncol Rep.2020;22:39.

7. Sunshine J, Taube JM. PD-1/PD-L1 inhibitors. CurrOpinPharmacol.2015;23:32-8.

8. McLaughlin J, Han G, Schalper KA, Carvajal-Hausdorf D, Pelekanou V, Rehman J, et al. Quantitative assessment of the heterogeneity of PD-L1 expression in non-small-cell lung cancer. JAMA Oncol.2016;2:46-54.

9. Carbone DP, Reck M, Paz-Ares L, Creelan B, Horn L, Steins M, et al. First-line nivolumab in Stage IV or recurrent non-small-cell lung cancer. N Engl J Med.2017;376:2415-26.

10. Lænkholm AV, Jensen MB, Eriksen JO, Rasmussen BB, Knoop AS, Buckingham W, et al. PAM50 risk of recurrence score predicts 10-year distant recurrence in a comprehensive Danish cohort of postmenopausal women allocated to 5 years of endocrine therapy for hormone receptor-positive early breast cancer. J Clin Oncol.2018;36:735-40.

11. Travis WD, Brambilla E, Noguchi M, Nicholson AG, Geisinger KR, Yatabe Y, et al. International Association for the Study of Lung Cancer/American Thoracic Society/European Respiratory Society international multidisciplinary classification of lung adenocarcinoma. J Thorac Oncol Off Publ Int Assoc Study Lung Cancer.2011;6:244-85.

12. Rekhtman N, Roy-Chowdhuri S. Cytology specimens: A goldmine for molecular testing. Arch Pathol Lab Med.2016;140:1189-90.

13. Gandhi L, Rodríguez-Abreu D, Gadgeel S, Esteban BSE, Felip E, Angelis FD, et al. Pembrolizumab plus chemotherapy in metastatic non-small-cell lung cancer. N Engl J Med.2018;378:2078-92.

14. Hou Z, Liang X, Wang X, Zhou Z, Shi D. Myeloid-derived suppressor cells infiltration in non-small-cell lung cancer tumor and MAGE-A4 and NY-ESO-1 expression.Oncol Lett. 2020;19:3982-92.

15. Davari K, Holland T, Prassmayer L, Longinotti G, Ganley KP, Pechilis LJ, et al. Development of a CD8 co-receptor independent T-cell receptor specific for tumor-associated antigen MAGE-A4 for next generation T-cell-based immunotherapy.J Immunother Cancer. 2021;9:e002035.

16. Chamuleau ME, Ossenkoppele GJ, van de Loosdrecht AA. MHC class II molecules in tumour immunology: Prognostic marker and target for immune modulation. Immunobiology.2006;211:61925.

17. Campoli M, Ferrone S. Hla antigen and NK cell activating ligand expression in malignant cells: A story of loss or acquisition. Semin Immunopathol.2011;33:321-34.

18. Reyes SB, Narayanan AS, Lee HS, Tchaicha JH, Aldape KD, Lang FF, et al. av $\beta 8$ integrin interacts with RhoGDI1 to regulate Rac1 and Cdc42 activation and drive glioblastoma cell invasion. Mol Biol Cell.2013;24:474-82. 
19. Astudillo P. Wnt5a signaling in gastric cancer. Front Cell Dev Biol.2020;8:110.

20. Kitamura K, Sakata J, Kangawa K, Kojima M, Matsuo H, Eto T. Cloning and characterization of cDNA encoding a precursor for human adrenomedullin. BiochemBiophys Res Commun.1993;194:720-5.

21. Kato $\mathrm{H}$, Shichiri M, Marumo F, Hirata Y. Adrenomedullin as an autocrine/paracrine apoptosis survival factor for rat endothelial cells. Endocrinology.1997;138:2615-20.

22. Buyukberber S, Sari I, Camci C, Buyukberber NM, Sevinc A, Turk HM. Adrenomedullin expression does not correlate with survival in lung cancer. Med Oncol.2007;24:245-9.

23. Hagman H, Bendahl PO, Melander O, Sundberg J, Johnsson A, Belting M. Vasoactive peptides associate with treatment outcome ofbevacizumab-containing therapy in metastatic colorectal cancer. Acta Oncol.2017;56:653-60.

24. Fukumura D, Kloepper J, Amoozgar Z, Duda DG, Jain RK. Enhancing cancer immunotherapy using antiangiogenics: Opportunities and challenges. Nat Rev Clin Oncol.2018;15:325-40.

25. Li SJ, Chen JX, Sun ZJ. Improving antitumor immunity using antiangiogenic agents: Mechanistic insights, current progress, and clinical challenges. Cancer Commun (Lond). 2021.

26. Ayers M, Lunceford J, Nebozhyn M, Murphy E, Loboda A, Kaufman DR, et al. IFN-gamma-related mRNA profile predicts clinical response to PD-1 blockade. J Clin Invest.2017;127:2930-40.

27. Damotte D, Warren S, Arrondeau J, Boudou-Rouquette P, Mansuet-Lupo A, Biton J, et al. The tumor inflammation signature (TIS) is associated with anti-PD-1 treatment benefit in the CERTIM pancancer cohort. J Transl Med.2019;17:357.

\section{Tables}

Table 1 Baseline Clinical Characteristics of All Patients. 


\begin{tabular}{|c|c|c|}
\hline Patient characteristics & $\begin{array}{l}\text { All patients } \\
(n=42)\end{array}$ & $\%$ \\
\hline \multicolumn{3}{|l|}{ Age (years) } \\
\hline Median (range) & \multicolumn{2}{|l|}{$69(43-85)$} \\
\hline$<70$ & 23 & 54.8 \\
\hline$\geq 70$ & 19 & 45.2 \\
\hline \multicolumn{3}{|l|}{ Sex } \\
\hline Male & 34 & 81.0 \\
\hline Female & 8 & 19.0 \\
\hline \multicolumn{3}{|l|}{ Smoking history } \\
\hline Never & 5 & 11.9 \\
\hline Current or former & 37 & 88.1 \\
\hline \multicolumn{3}{|l|}{ Histology } \\
\hline Adenocarcinoma & 20 & 47.6 \\
\hline Squamous cell carcinoma & 22 & 52.4 \\
\hline \multicolumn{3}{|l|}{ EGFR mutation status } \\
\hline Del-19 & 1 & 2.4 \\
\hline Exon 18 & 1 & 2.4 \\
\hline Wild type & 22 & 52.4 \\
\hline Unknown & 18 & 42.8 \\
\hline \multicolumn{3}{|l|}{ PD-L1 (TPS) } \\
\hline 0 & 2 & 4.8 \\
\hline $5-49$ & 3 & 7.1 \\
\hline$\geq 50$ & 5 & 11.9 \\
\hline Unknown & 32 & 76.2 \\
\hline \multicolumn{3}{|c|}{ Number of previous chemotherapy regimen } \\
\hline 1 & 22 & 52.4 \\
\hline 2 & 8 & 19.0 \\
\hline$\geq 3$ & 12 & 28.6 \\
\hline
\end{tabular}




\begin{tabular}{|lcc|}
\hline Number of administrations & & \\
\hline $1-5$ & $9(1-64)$ & 26.2 \\
\hline $6-10$ & 11 & 31.0 \\
\hline $11-30$ & 13 & 23.8 \\
$\geq 31$ & 10 & 19.0 \\
\hline Type of specimen material & 8 & \\
\hline Brush & 29 & 69.1 \\
\hline TBB & 8 & 19.0 \\
\hline FNA (Lymph node) & 4 & 9.5 \\
\hline CTGB & 1 & 2.4 \\
\hline $\begin{array}{l}\text { EGFRepidermal growth factor receptor,Del-1919 deletion, PD-L 1programmed cell death ligand } \\
\text { 1,TPSTumor Proportion Score, TBB transbronchial biopsy,FNA fine-needle aspiration, CTGB computed } \\
\text { tomography guided biopsy }\end{array}$ & \\
\hline
\end{tabular}

Table2 Summary of Antitumor Activity.

\begin{tabular}{|lll|}
\hline All patients & $\mathrm{n}$ & $\%$ \\
$(\mathrm{n}=42)$ & & \\
\hline Type of response & & \\
\hline $\mathrm{PR}$ & 18 & 42.8 \\
$\mathrm{SD}$ & 11 & 26.2 \\
\hline $\mathrm{PD}$ & 13 & 31.0 \\
\hline & & \\
\hline Objective response rate & & 42.8 \\
\hline Disease control rate & & 69.0 \\
\hline PR partial response,SD stable disease, $P D$ progressive disease \\
\hline
\end{tabular}

Table3 Summary of Overall Response Rate (ORR) 


\begin{tabular}{|c|c|c|}
\hline $\begin{array}{l}\text { All patients } \\
(n=42)\end{array}$ & $\mathrm{n}$ & $\%$ \\
\hline Histology & \multicolumn{2}{|l|}{42} \\
\hline \multicolumn{3}{|l|}{ Adenocarcinoma } \\
\hline ORR & $7 / 20$ & 35.0 \\
\hline \multicolumn{3}{|c|}{ Squamous cell carcinoma } \\
\hline \multirow[t]{2}{*}{ ORR } & $11 / 22$ & 50.0 \\
\hline & \multicolumn{2}{|c|}{$p=0.367^{\star}$} \\
\hline EGFR mutation status & \multicolumn{2}{|l|}{24} \\
\hline \multicolumn{3}{|l|}{ Positive } \\
\hline ORR & $0 / 2$ & 0 \\
\hline \multicolumn{3}{|l|}{ Wild-type } \\
\hline \multirow[t]{2}{*}{ ORR } & $8 / 22$ & 36.4 \\
\hline & \multicolumn{2}{|c|}{$p=0.536^{*}$} \\
\hline PD-L1 (TPS) & \multicolumn{2}{|l|}{10} \\
\hline \multicolumn{3}{|l|}{$\geq 1 \%$} \\
\hline ORR & $5 / 8$ & 62.5 \\
\hline \multicolumn{3}{|l|}{$<1 \%$} \\
\hline \multirow[t]{2}{*}{ ORR } & $2 / 2$ & 100.0 \\
\hline & \multicolumn{2}{|c|}{$p=0.467^{\star}$} \\
\hline *Fisher's exact test & & \\
\hline
\end{tabular}

Figures 
A

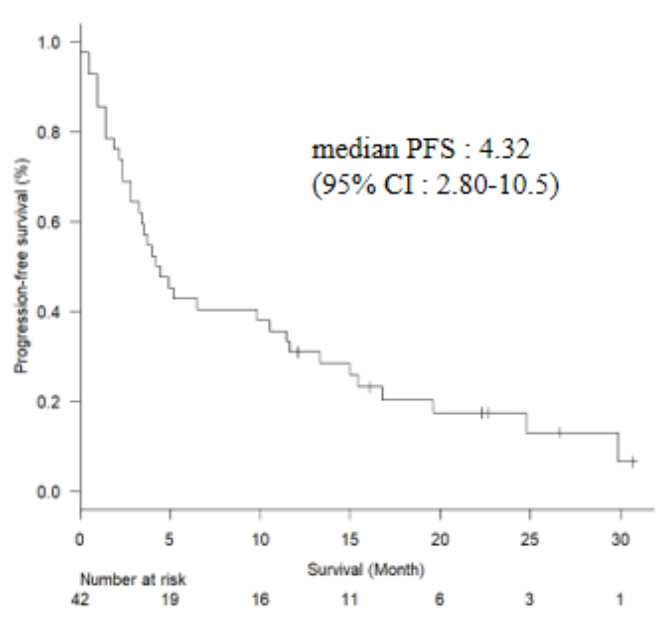

$\mathrm{C}$

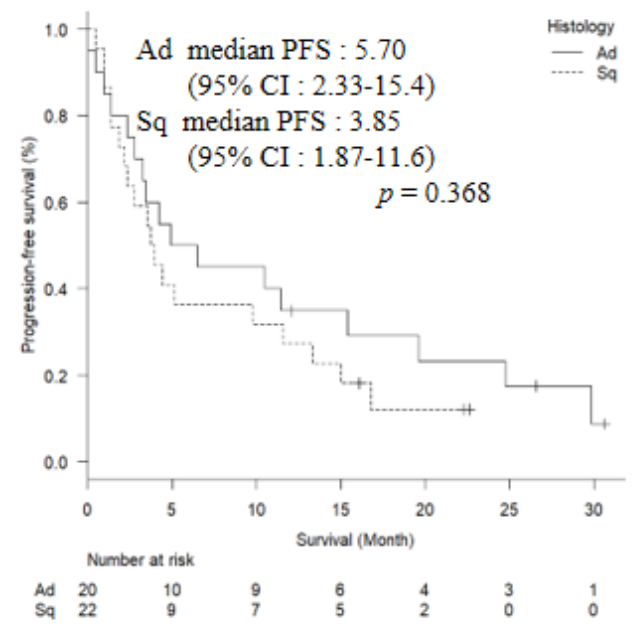

B

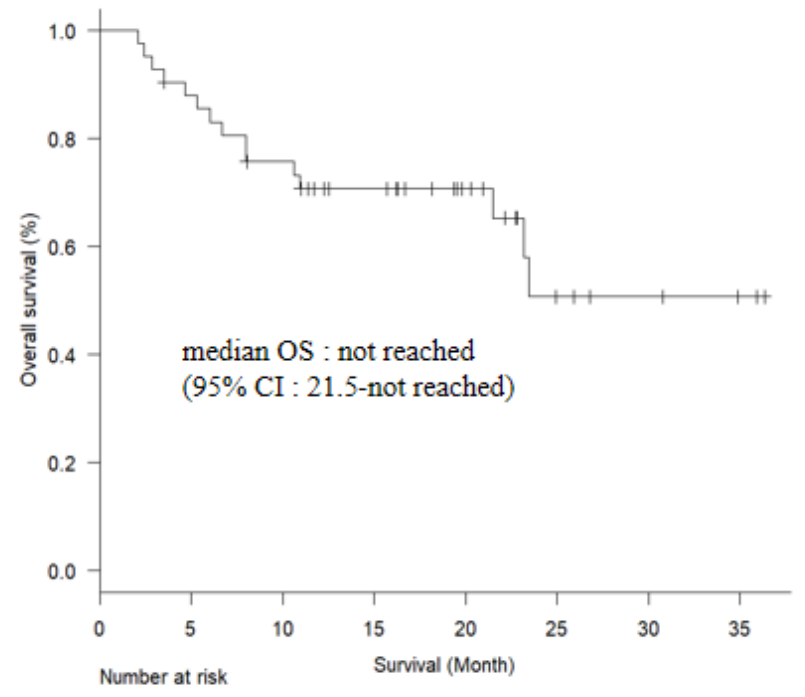

$\mathrm{D}$

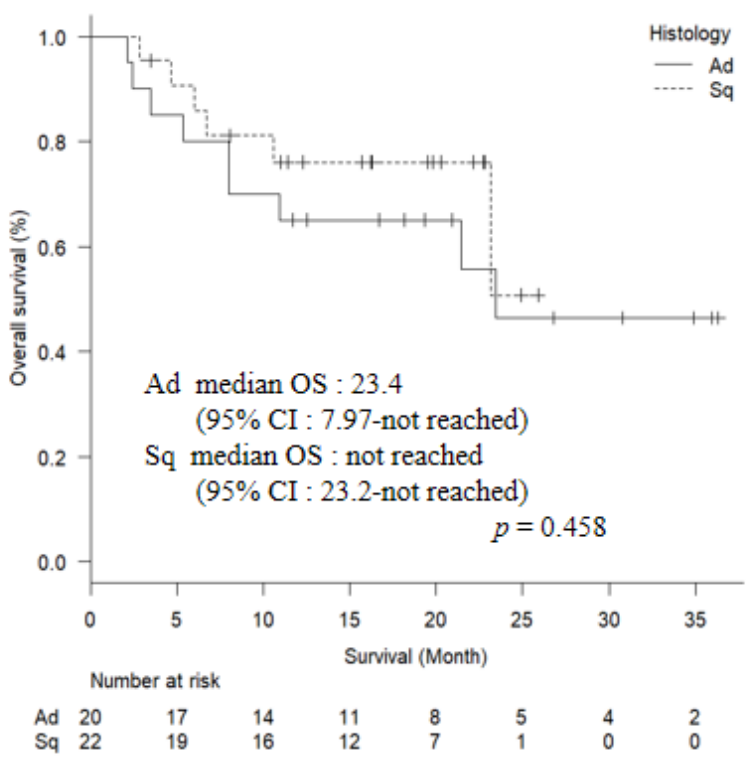

Figure 1

Progression-free survival (A) and overall survival (B) for all the patients. Progression-free survival (C) and overall survival (D) classified by histological type. Solid line indicates adenocarcinoma and dashed line indicates squamous cell carcinoma. 
A

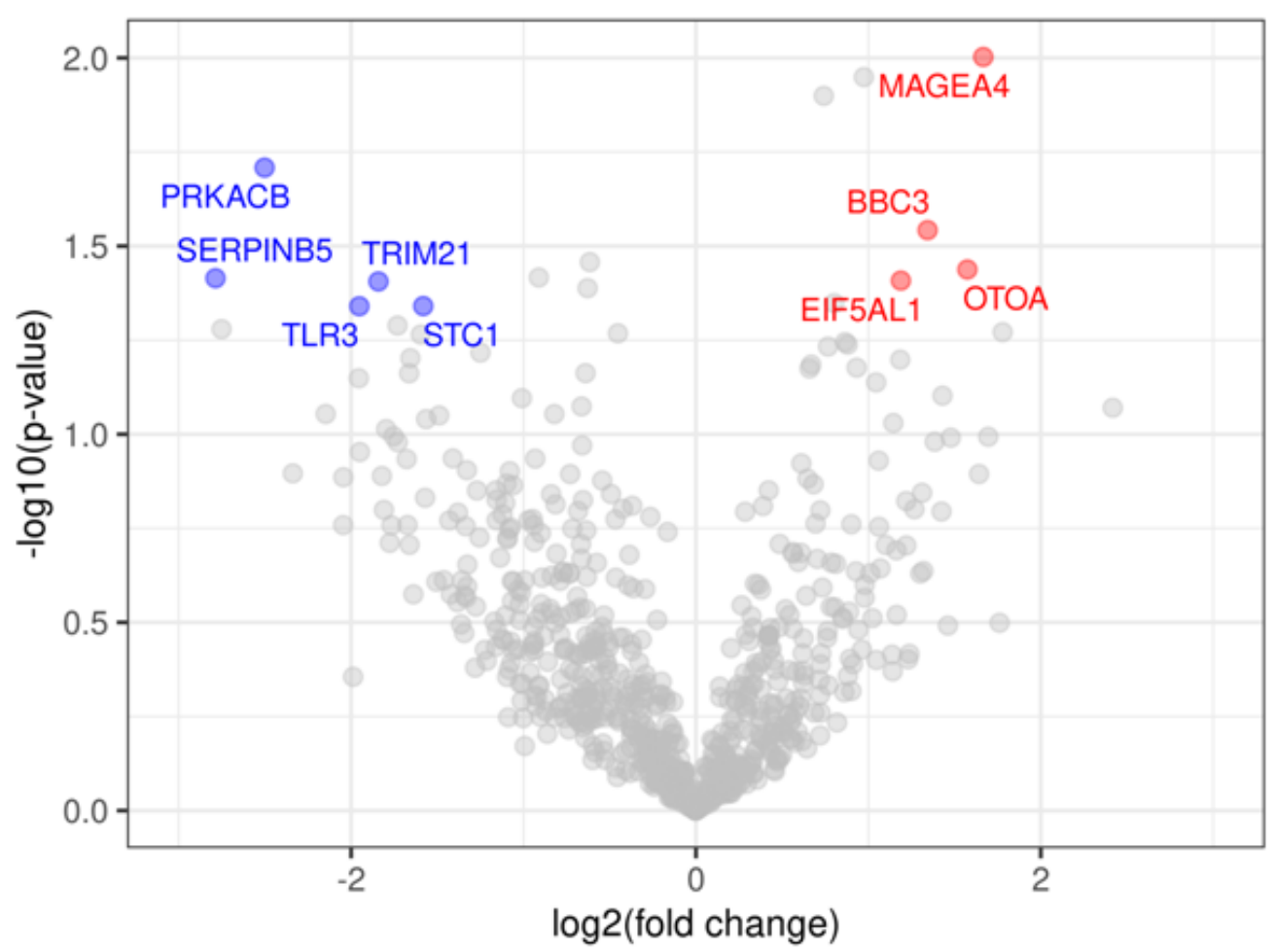

B

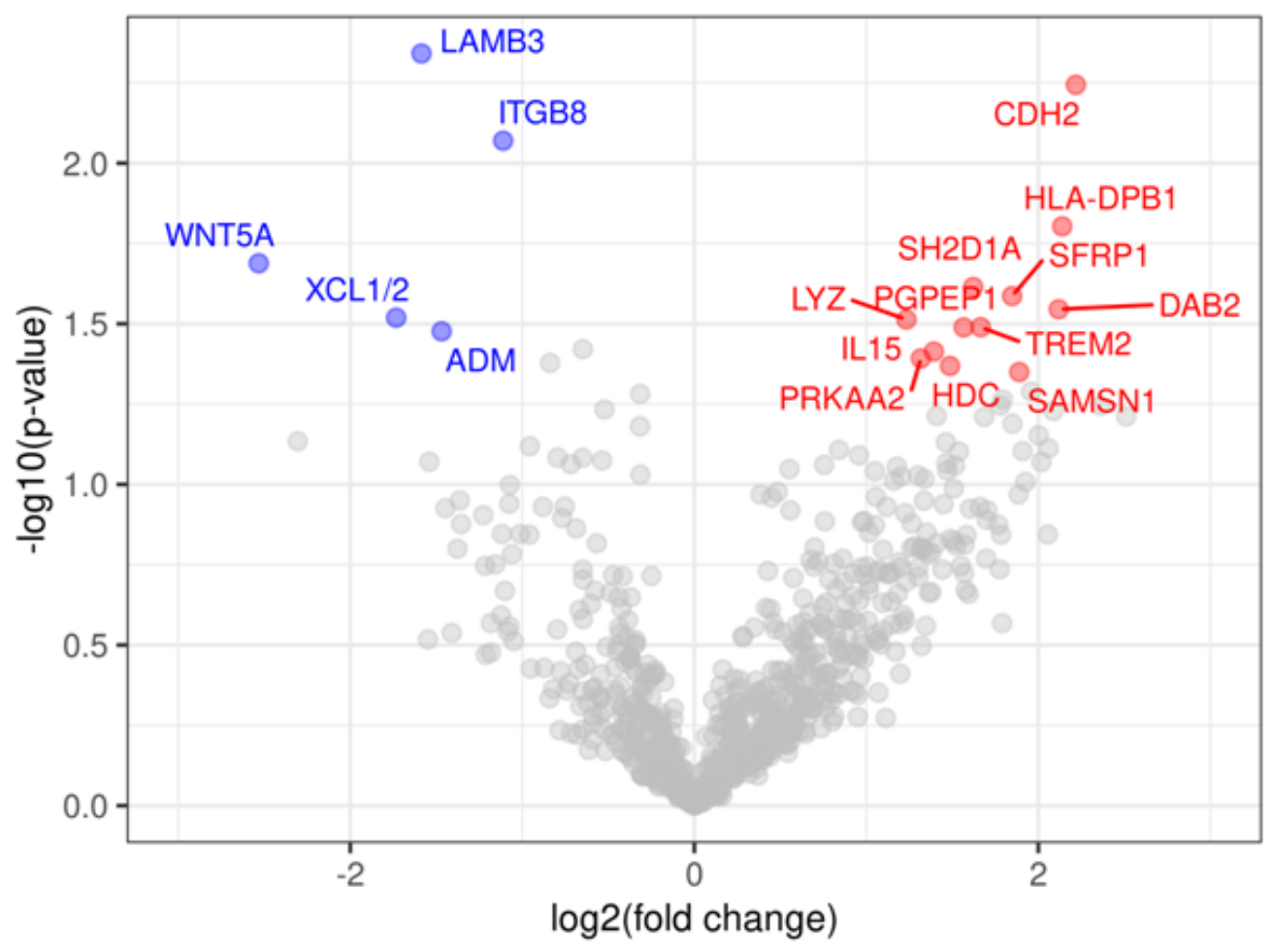

\section{Figure 2}

Volcano plot of unadjusted $p$ value versus log2 fold change of the differential expression between responders $(P R)$ and non responders (PD/SD) in adenocarcinoma $(A)$ and squamous cell carcinoma cohort (B). The test for differential expression was performedusing Welch's $t$-test. Dots corresponding to genes with $\mathrm{P}<0.05$ and with expression 1.5 -fold higher than those in non-responders are labeled in red, and those with $\mathrm{P}<0.05$ and expression 1.5 -fold higher than those in responders are labeled in blue. 
A

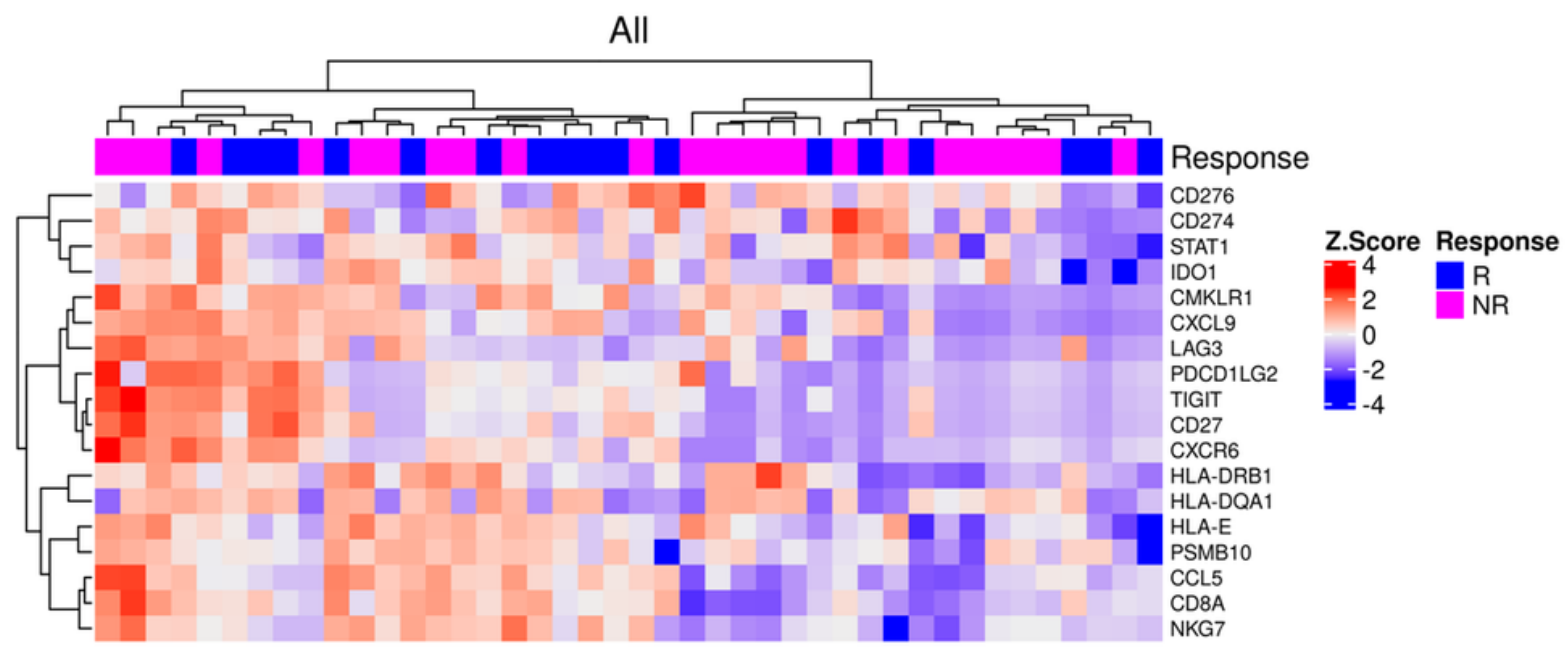

$\mathrm{B}$

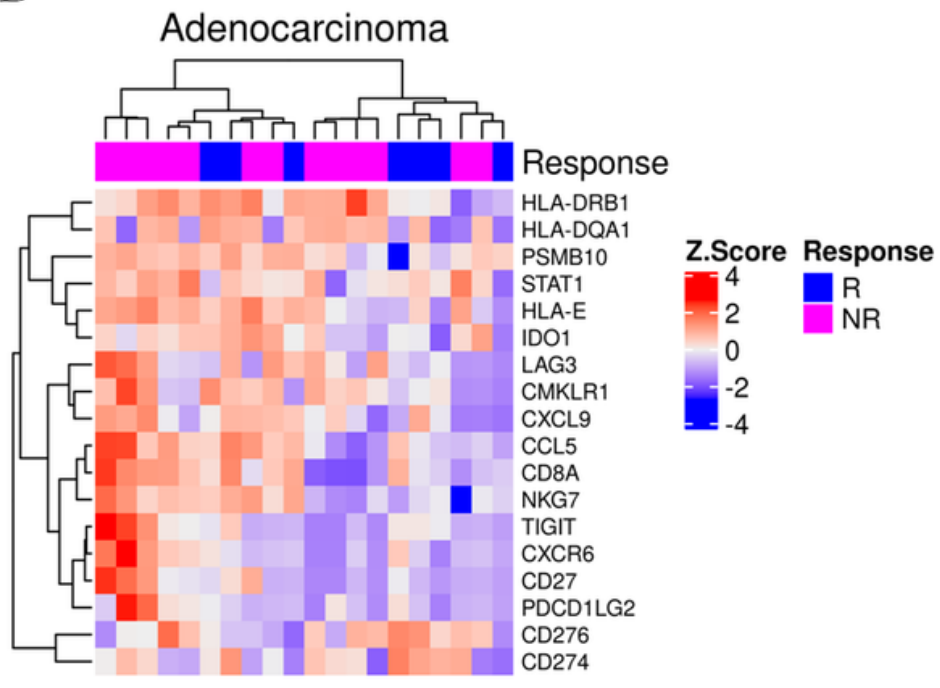

$\mathrm{C}$

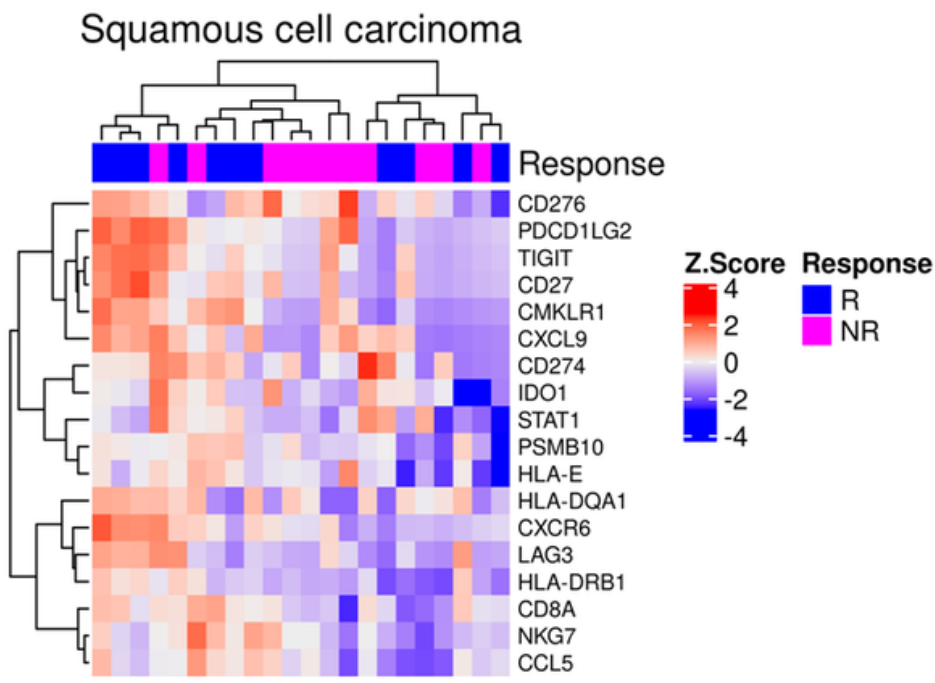

\section{Figure 3}

Heatmap for tumor inflammation signature (TIS) profile considered evaluable for objective response for all cases (A), adenocarcinoma (B), and squamous cell carcinoma (C).Columns represent patients and rows represent genes. The expression levels have been scaled within rows for visualization. The top row shows whether the patient was a responder (magenta) or a non-responder (blue). 